\title{
¿Se puede considerar formal la lógica de Aristóteles?
}

\author{
Can Aristotle's Logic be Considered a Formal Logic?
}

\author{
JOSÉ MARÍA LLOVET ABASCAL*
}

\begin{abstract}
Resumen: En este trabajo planteo la pregunta de si la lógica de Aristóteles es o no una lógica formal. Respondo que, aunque las doctrinas contenidas en el Organon inauguren, efectivamente, la lógica formal, hay también buenas razones para pensar que Aristóteles no creía que la lógica fuese una disciplina que pudiera prescindir por completo del contenido.

Palabras clave: Aristóteles, lógica formal, inferencia inmediata, demostración.
\end{abstract}

\begin{abstract}
In this paper I discuss the question of whether Aristotle's logic is a formal logic or not. I answer that, although the doctrines contained in the Organon inaugurate indeed formal logic, there are also good reasons to think that Aristotle did not believe that logic was a discipline that ought to prescind completely from content.
\end{abstract}

Keywords: Aristotle, Formal logic, Immediate Inference, Demonstration.

\section{Introducción}

¿Qué clase de proyecto está contenido en los Analíticos de Aristóteles y, en general, en todo el Organon? ¿Es correcto afirmar que Aristóteles inaugura la lógica formal con sus doctrinas sobre el juicio y el silogismo? Para responder a esta pregunta, a continuación haré un breve recuento de cómo fue que Aristóteles descubrió y concibió inicialmente la lógica. Ello me permitirá explicar por qué Aristóteles admitió las inferencias inmediatas y por qué no admitió los silogismos de cuarta figura.

\section{El Organon de Aristóteles y la inauguración de la lógica formal}

Empecemos por considerar la cuestión de cuál es exactamente el tema de los Analíticos. Tradicionalmente se ha considerado que el tema de Analíticos primeros es diferente al de los Analíticos posteriores: el primero trataría de la deducción ( $\sigma v \lambda \lambda o \gamma\llcorner\sigma \mu o ́ \varsigma)$ y el segundo de

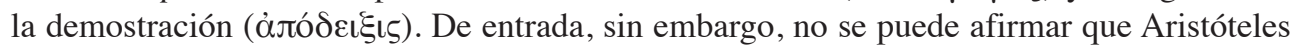
haya concebido dos tratados distintos, uno dedicado a la deducción y otro a la demostra-

Recibido: 04/10/2018. Aceptado: 16/09/2019.

* Departamento de Humanidades, Universidad Panamericana, Campus México. Su investigación se centra actualmente en la filosofía teórica de Kant y la filosofía teórica de Aristóteles, especialmente filosofía de la naturaleza y metafísica. Publicaciones más recientes: (2019) "El origen psicológico de los conceptos empíricos en la Crítica de la razón pura”. Open Insight. Vol. 10, núm. 19. Pp. 81-98; (2019) Reseña de Niels Engelsted "Catching Up with Aristotle: a Journey in Quest of General Psychology”. Diánoia. Vol. 64, núm. 82. Pp. 192-195. jllovet@up.edu.mx 
ción, pues sabemos que el orden en el que los Analíticos nos llegaron no se corresponde necesariamente con el orden original de composición y disposición. Aristóteles suele refe-

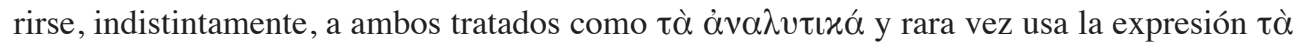

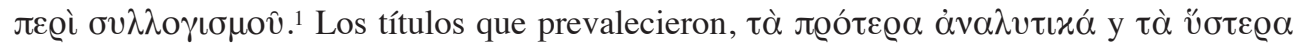
$\dot{\alpha} v \alpha \lambda v \tau \iota x \alpha ́$ aparecen ya en el catálogo de Diógenes de las obras de Aristóteles. Alejandro los recibió ya separados y escribió comentarios a ambos, aunque el comentario a los Analíticos posteriores se perdió. Una muestra de que Aristóteles los concebía como un todo unitario es que al inicio de los Analíticos primeros afirma que el tema de su investigación es la demostración. Esto lo hace en las primeras líneas, antes de comenzar a explicar qué es una deduc-

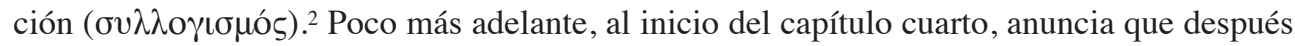
se hablará de la demostración, pues "hay que hablar antes de la deducción ( $\sigma v \lambda \lambda o \gamma(\sigma \mu o ́ \varsigma)$, por ser la deducción más universal que la demostración: en efecto, la demostración es un cierto tipo de deducción, pero las deducciones no son todas demostraciones". ${ }^{3}$ Vuelve a referirse a la demostración en otros ocho pasajes de los Analíticos primeros ${ }^{4} \mathrm{Y}$ en el último capítulo de los Analíticos posteriores recapitula: "Sobre la deducción y la demostración, entonces, qué es cada uno de ellos y cómo se constituye es manifiesto, y al mismo tiempo para la ciencia demostrativa: son lo mismo". 5 Jonathan Barnes (1981, p. 27) explica que "los Analíticos primeros son didácticamente anteriores que los Analíticos posteriores: Aristóteles considera su silogística una propedéutica de la apodíctica, y supone que hemos leído los Analíticos primeros antes de embarcarnos en los Posteriores" (Barnes, 1981, p. 27).

Las razones por las cuales el editor — probablemente Andrónico (During, 2000, p. 102)— los separó en Analíticos primeros y Analíticos posteriores están suficientemente justificadas: en efecto, el hilo conductor de los capítulos que conforman los Analíticos primeros es la deducción, y el de los Analíticos posteriores, la demostración. Esta división, sin embargo, ha dificultado a menudo una lectura unitaria de ambos libros, pues se lee el primero como un libro de lógica y el segundo como un libro sobre la teoría aristotélica de la ciencia demostrativa. En realidad, la división en lógica y teoría de la ciencia no es aristotélica: él consideraba la investigación sobre la deducción como parte de una investigación más amplia — pero no independiente - sobre la ciencia demostrativa.

No es fácil por ello, en una primera aproximación, comprender qué clase de proyecto está plasmado en los Analíticos. Históricamente, es cierto que los Analíticos primeros inauguran la lógica formal. J. M. Bochenski asegura que antes de él no hay registro de "un estudio de leyes o reglas lógicas, aunque algunas de ellas fueron usadas conscientemente desde Zenón de Elea, y Platón trató, sin éxito, de desarrollar una lógica” (Bochenski, 1951, p. 9). Al final de los Elencos sofísticos, Aristóteles se proclama como el descubridor de la deducción: "Sobre la retórica mucho se había dicho desde tiempo atrás, mientras que sobre la

$1 \tau \grave{\alpha} \alpha \dot{\alpha} \alpha \lambda v \tau \tau x \alpha ́$ es usado para referir a los Analíticos primeros en De int. 10, 19b31, y para referir a los Analíti-

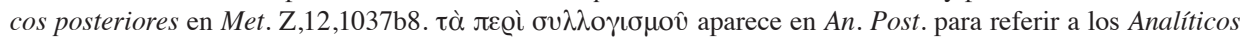
primeros en I,3,73a14 y en I,11,77a34.

2 An.Pr. I, 1,24a10.

3 An. Pr. I,4,25b26-28.

4 An.Pr. 32b18; 40b23; 46a36; 46b38; 64b32; 65a36; 68b10.

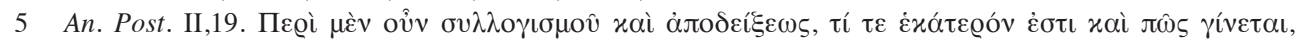

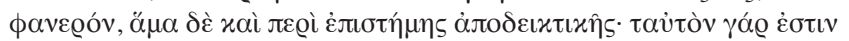


deducción nada cabe mencionar que fuese anterior". ${ }^{6}$ Puesto que suele reconocer deudas con antecesores en la mayoría de sus escritos, podemos suponer que realmente se consideraba el fundador de algo nuevo. Según W.D. Ross, debió estar "probablemente más orgulloso de sus logros en la lógica que de cualquier otra parte de su pensamiento filosófico" (Ross, 1949 , p. 23). Pero ¿cuál era exactamente este logro? Aristóteles no tiene para la lógica ni siquiera un nombre. ¿Realmente llevó a cabo una investigación estrictamente formal sobre la validez de ciertos razonamientos, como entendemos, en general, la lógica hoy en día? Creo que las doctrinas expuestas en los Analíticos primeros, De interpretatione y los Tópicos pueden ser llamadas con todo derecho "lógicas", siempre y cuando se añadan los matices correspondientes para no atribuir a Aristóteles una concepción de la lógica —más cercana a la nuestra - que le fue completamente ajena.

La lógica se inscribe para Aristóteles dentro de lo que hoy llamamos epistemología, pues

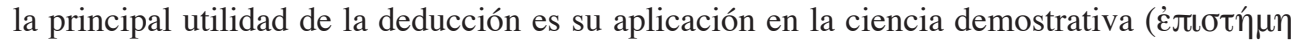

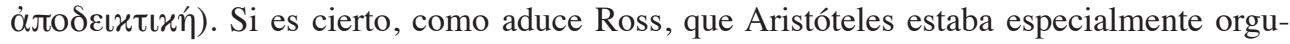
lloso de sus logros en la lógica, no debió ser sólo a causa de su originalidad, del grado de refinamiento que alcanzó, ni de la profundidad con la que abordó ciertos temas. Bajo este criterio, otras doctrinas suyas podrían quizá estimarse tanto o más. La razón del orgullo con el que se refiere a la teoría de la deducción al final de los Elencos sofísticos - que cierra, además, pidiendo que se le agradezca por tal logro - tiene que ver más con lo que él cree haber conseguido por medio de ella: dar cuenta del tipo de conocimiento más valioso que

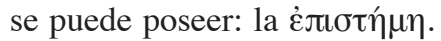

Según H. Maier, lo que motivó a Aristóteles a llevar a cabo sus investigaciones lógicas fue el deseo de oponer resistencia al escepticismo de las escuelas megárica, cínica y cirenaica, principalmente: "Él creía, como Platón, en la posibilidad de una ciencia exacta y superior, eternamente válida y por encima de la alternancia de la opinión" (Maier, 1897, p. 57). ${ }^{7}$ Para Platón esa ciencia exacta y superior se identificaba con la dialéctica. ${ }^{8}$ A Aristóteles la dialéctica de la Academia no le satisfizo y por ello su lógica constituye en buena medida su emancipación de la filosofía platónica con respecto al método para

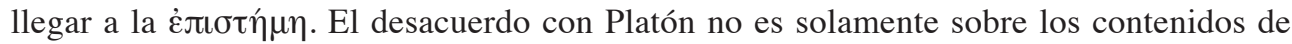
la $\dot{\varepsilon} \pi \iota \sigma \tau \hat{\mu} \eta$, sino también sobre sus condiciones y la manera de adquirirla y transmitirla. Lo que Aristóteles desarrolla en ambos Analíticos - que, como hemos dicho, consideraba unidos en un solo proyecto $-{ }^{9}$ es mucho más que una doctrina para distinguir los razonamientos correctos de los incorrectos. Es una epistemología que pretende dar cuenta de las condiciones del conocimiento demostrativo, el paradigma contra el cual deberá compararse cualquier otro tipo de saber. La dialéctica aristotélica, por su parte, abordada

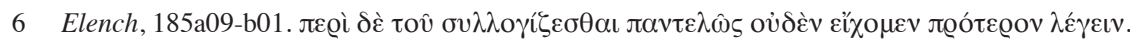

7 La visión de Maier no es compartida por R. Smith (2009), para quien la refutación del escepticismo es más bien una preocupación que inicia con Descartes. De todas maneras, a Aristóteles le interesaba tanto como a Platón justificar la posibilidad de un tipo de conocimiento superior al de la mera opinión. Un proyecto de esta naturaleza forzosamente implica, aunque sea indirectamente, un intento de refutación del escepticismo y del relativismo. Cf. Rep. 534c-d y Met. A:1.

8 Rep. 533a-c; 534b-d. Cf. (Stephens, 1993).

9 "Both the programme for the Analytics and its conclusions treat the work as a unitary whole. Cross-references

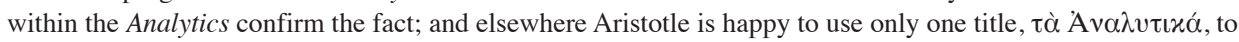
refer to either half of the treatise" (Barnes, 1981, p. 27) 
sobre todo en los Tópicos, es mucho más que una técnica para vencer en cualquier tipo de discusión; es una propedéutica de la ciencia y, además, su principal proveedora de contenidos. A través del ejercicio dialéctico se obtienen los principios a partir de los cuales la ciencia demostrativa debe proceder deductivamente.

La separación entre dialéctica y ciencia demostrativa, sin embargo, fue un proceso paulatino. A Aristóteles la dialéctica de la Academia debió parecerle una metodología inasible, carente de principios claros sobre su modo de proceder..$^{10}$ En los Tópicos, cuya anterioridad respecto de los Analíticos es hoy en día generalmente aceptada (Huby, 1962, pp. 6-7), intentó sistematizar las técnicas dialécticas. Se cree que debió componer por lo menos los libros II a VII durante sus últimos años en la Academia. Más tarde, además de hacer enmiendas en numerosos pasajes, añadió los libros I, VIII y IX —este último fue bautizado siglos después con el nombre de Elencos sofísticos-. Los Tópicos fueron entonces la primera etapa en el desarrollo de la lógica y de su concepción de la ciencia demostrativa. Según J. Hintikka, cuando Aristóteles analizó las preguntas polares (yes-or-no questions) usadas por Sócrates y Platón, se dio cuenta de que había algunas cuyas respuestas estaban lógicamente implícitas en respuestas anteriores. "A causa de su importancia estratégica, Aristóteles comenzó a estudiarlas, lo cual, claro, significó el estudio de las inferencias lógicas” (1997, p. 241). Este estudio de las inferencias lógicas dio como resultado su llamada silogística, contenida sobre todo en los Analíticos primeros. Aristóteles la desarrolló con tal agudeza que 21 siglos más tarde Kant afirmaría que no era posible agregarle nada.

Que la lógica aristotélica haya nacido a partir del análisis de la dialéctica de Platón no es algo trivial. Desde el punto de vista meramente lógico, el método de los é $\lambda \varepsilon \gamma \chi$ o - la técnica socrática de pregunta-respuesta - adquiere claridad gracias a la silogística de Aristóteles, pues ésta provee un criterio certero para determinar la validez o invalidez de los razonamientos. La dialéctica platónica, sin embargo, no es sólo un método argumentativo que se pueda sustituir o reformar fácilmente. No es un juego ni una gimnasia mental, aunque según R. Bolton (1990), así llegó a practicarse en ocasiones dentro de la Academia, ${ }^{11}$ razón por la cual Platón critica tan duramente su uso frívolo en la República y determina que al estudiante no se le debe instruir en ella sino hasta que cumpla los 30 años. ${ }^{12}$ Para Platón la dialéctica es la cornisa ( $\theta \varrho \iota \gamma x o ́ \varsigma)$ de todos los saberes $(\mu \alpha \theta \eta \dot{\eta} \mu \alpha \alpha)^{13}$ y el único método capaz de liberar de las cadenas de la ignorancia: ${ }^{14}$

10 "Dado que están sin determinar [las normas] para los que construyen argumentos con vistas a ejercitarse y ensayar [...], ya que no tenemos ningún dato suministrado por otros, intentaremos decir algo nosotros mismos". Tópicos VIII: 5, 159b25-39.

11 Sobre la Academia cf. (Cherniss, 1962).

12 Rep. 537c-540c

13 Rep. 534e.

14 "Y la liberación de las cadenas, proseguí, y la conversión de las sombras a los simulacros y a la luz; y la subida del subterráneo hacia el sol, con la impotencia del evadido, al llegar ahí, de percibir todavía los animales, las plantas y la luz solar, sino únicamente los reflejos divinos en la superficie de las aguas y las sombras de objetos reales, aunque ya no las sombras proyectadas por otra luz que, comparada con el sol, es de la misma condición tenebrosa: he ahí la virtud que posee el estudio de las ciencias que hemos pasado en revista. Eleva la mejor parte del alma a la contemplación del mejor de los seres, no de otro modo que, según vimos, asciende el más brillante de los órganos del cuerpo a la contemplación de lo que hay de más luminoso en el mundo corporal y visible". Rep. 532b-c. 
No hay otro método que se proponga, por esta vía y en cualquier materia, aprehender la esencia de cada cosa [...] El método dialéctico [...] es el único que, cancelando sucesivamente las hipótesis, sigue así su camino hasta el principio mismo para asentarlo firmemente; el único que verdaderamente saca al ojo del alma, con toda suavidad, del bárbaro lodazal en que estaba sumido y lo eleva hacia lo alto. ${ }^{15}$

La dialéctica era para Platón el único método válido para hacer filosofía, pues la filosofía era para él una conversación. El método de la pregunta-respuesta permitía confirmar los descubrimientos con otras personas - Sócrates cita en el Protágoras las palabras de Diomedes en la Ilíada: "Marchando los dos juntos, el uno alcanza a ver antes que el otro"- ${ }^{16}$ y obligaba a que las investigaciones procedieran de una manera clara para todos - en el Gorgias, Sócrates dice: “¿Por qué, sospechando yo mismo, te preguntaré y no lo digo yo mismo? No por ti, sino por la conversación, para que prosiga de tal manera que se nos haga lo más manifiesto posible aquello acerca de lo cual se habla" -.${ }^{17}$ Además, como explica en el Fedro, la escritura hace a las personas olvidadizas y no puede responder preguntas. ${ }^{18} \mathrm{La}$ dialéctica es el único camino válido para alcanzar la verdadera sabiduría y, como explica J. Stephens, tiene además un ingrediente purificador:

La dialéctica conduce al individuo al conocimiento operando una katharsis, una purificación, o una therapeia, una cura o sanación del alma. Por consiguiente, en el Fedón ${ }^{19}$ la "persuasión" filosófica libera el alma de la contaminación del cuerpo y los sentidos; en la República la dialéctica aleja el alma del "lodazal barbárico del mito órfico"; en el Fedro, ${ }^{20}$ la entrada en la vida filosófica es consecuencia de que el poder del mal en el alma sea superado a través de la conversación filosófica de los amantes; y en el Banquete ${ }^{21}$ la instrucción filosófica sobre el eros colma el vacío en el alma que define la necesidad erótica (Stephens, 1993, p. 467).

Platón le atribuye este poder liberador y purificador a la dialéctica porque cree que es el único método mediante el cual es posible alcanzar la غ̇лı $\tau \eta \dot{\mu \eta} .{ }^{22}$ En la República, explica

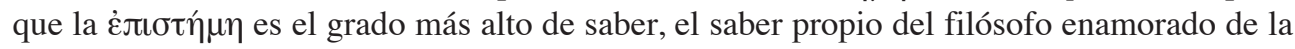
$\operatorname{verdad}^{23}$, mientras que la $\delta$ ó $\xi \alpha$ es propia del hombre vulgar que se regocija con los espectáculos sensuales. ${ }^{24}$ Esta división tiene implicaciones metafísicas que concuerdan con su

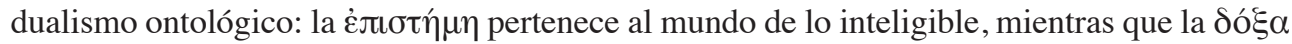
al mundo de las apariencias. El vínculo entre epistemología y metafísica se aprecia también

15 Rep. 533b-d.

16 Prot. 348d. Ilíada X 224.

17 Grg. 453c. La referencia la encontré en J. Stephens, op. cit.

18 Phdr. 274c.

19 Phd. 66b; cf. $81 \mathrm{~b} \&$ ss, 82d-83a.

20 Phdr. 255b, 256b.

21 Symp. 211d.

22 Cf. Rep. 534, 535.

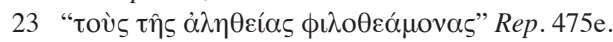

24 Rep. 476-478. 
en su doctrina de la reminiscencia ( $\alpha$ vó $\mu \nu \eta \sigma \iota \varsigma)$, pues de acuerdo con Aristóteles, fue la necesidad de dar cuenta de los universales la que lo llevó a plantear la teoría de las Formas. ${ }^{25}$

Cuando Aristóteles comenzó a analizar y sistematizar la dialéctica en sus Tópicos, no

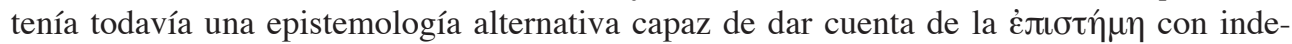
pendencia de la dialéctica platónica. No podemos saber si ya desde entonces sospechaba

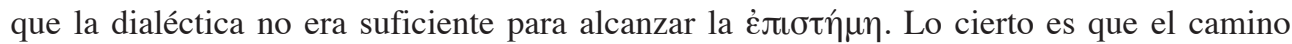

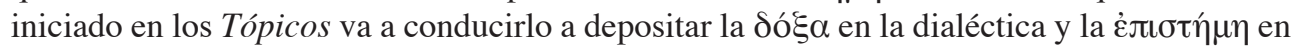
la demostración. La afirmación de que la dialéctica procede a partir de opiniones reputables

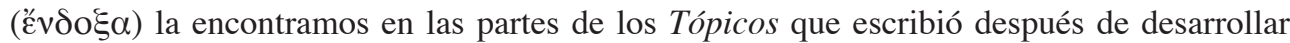

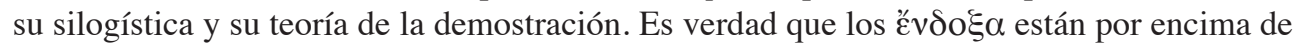
la mera $\delta o ́ \xi \alpha$, pues son opiniones sostenidas por la autoridad de los sabios, los ancianos o la mayoría, pero siguen siendo opiniones. Lo relevante, desde mi punto de vista, es entonces lo siguiente: la emancipación de Aristóteles de la dialéctica platónica implicó también una emancipación de los presupuestos metafísicos y epistemológicos —en particular, de las doctrinas de las Formas y la óvó $\mu v \eta \sigma \iota \varsigma$, con todas sus consecuencias - en los cuales se fundaba su carácter de "método único y absoluto" ${ }^{26} \mathrm{El}$ andamiaje platónico resultaba enormemente sólido porque era, de alguna manera, circular: el problema epistemológico de los universales llevaba a la teoría metafísica de las Formas; pero a su vez, la teoría de las Formas constituía el fundamento de la epistemología platónica (cf. White, 2006). Además, como apunta H. Maier, la dialéctica tenía la facultad de autojustificarse (1897, p. 45). Lo que Aristóteles hace en los Analíticos segundos es elaborar una epistemología que no necesita de la doctrina de las Formas ni de la óvó $\mu v \eta \sigma ı \varsigma$ y que se desprende de alguna manera de su silogística. Su estrategia es la siguiente: puesto que gracias a la silogística poseemos un criterio seguro para evaluar la validez de los razonamientos, ahora es preciso determinar en virtud de qué las proposiciones usadas en ellos son verdaderas o falsas. La verdad o falsedad de las proposiciones no puede ser determinada por la lógica: ésta sólo puede decretar si hay o no consistencia entre las proposiciones que se sostienen. La dialéctica platónica buscaba también establecer si había consistencia entre una serie de proposiciones. Su ventaja, sin embargo, radicaba en que la verdad o falsedad de tales proposiciones podía determinarse también por medio de ella. ${ }^{27}$ Para Platón la dialéctica se alimenta de una fuente de conocimiento independiente de las "imágenes", pues toma contacto por sí misma con los objetos originales e inteligibles. El modelo platónico del conocimiento va a ser tomado por Aristóteles como base para desarrollar su propia epistemología, con una diferencia capital: para él, todo conocimiento se origina en la experiencia. Esta tesis tiene una consecuencia degradadora para la dialéctica: si todo conocimiento se origina en la experiencia, entonces la dialéctica sólo puede encargarse de enfrentar dinámicamente una serie de proposiciones para encontrar consistencias o inconsistencias entre ellas. La dialéctica no tiene acceso a una fuente privilegiada de conocimiento, los “objetos originales". Los contenidos con los que opera dependen, en última instancia, de la experiencia.

25 Cf. Met A:6 987b01-09.

26 “Onhe Dialektik keine Philosophie, und ohne Philosophie keine Dialektik: der echte Philosoph muss Dialektiker, der wahre Dialektiker Philosoph sein" (Maier, 1897, p. 28). Cf. Soph. 253b-e. Phaedr. 266b; 265d.

27 Cf. Soph. 253c-d. Rep. 510b, 511b \& 532a-b. 
La posición empirista de Aristóteles exige reformular el modelo platónico de ascenso a lo inteligible, sin recurrir a "trampolines" ni "peldaños". Se enfrenta con el eterno problema de cualquier empirismo: ¿cómo es posible alcanzar la غ̇ंı miento es la experiencia? ¿Cómo pasamos de la experiencia particular y contingente provista por los sentidos a un conocimiento universal y necesario? La solución a este problema va a ser la teoría de la demostración. Apoyándose en su silogística, Aristóteles propone que tene-

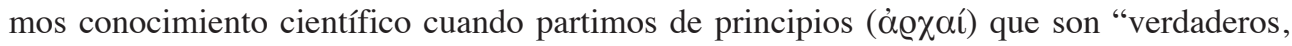
primitivos, inmediatos y más conocidos, más explicativos y anteriores que la conclusión". ${ }^{28}$ Proceder deductivamente a partir de esos principios es demostrar.

La relevancia de los principios se explica así: la silogística sólo puede, deductivamente, mostrar si hay consistencia entre una serie de proposiciones y desarrollar todas sus consecuencias lógicas. Pero la consistencia es independiente de la verdad o falsedad de las proposiciones. La verdad de una proposición cualquiera no se puede probar deductivamente: aunque sea la conclusión de una deducción formalmente válida, si una de las premisas de esa deducción es falsa, la conclusión puede ser verdadera o falsa. Cuando la deducción es válida y parte de premisas verdaderas, entonces la verdad de estas premisas se extiende a la conclusión: pero esta "verdad deductiva" - el que se pueda afirmar que tal proposición es verdadera porque se deduce de otras proposiciones verdaderas - depende siempre de que las proposiciones anteriores sean verdaderas. Necesitamos, entonces, principios verdaderos para demostrar a partir de ellos, pero esos principios no pueden ser también demostrados porque entonces necesitarían, a su vez, de principios. Los principios deben ser indemostrables y, sin embargo, verdaderos y en eso radica la posibilidad de la

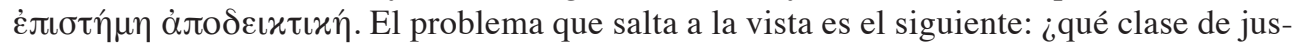
tificación tienen tales principios? ¿Cómo es que los poseemos, si, como afirma Aristóteles, todo conocimiento comienza con la experiencia? ¿Y qué clase de capacidad intelectual da cuenta de su adquisición? Además, ¿cómo podemos estar seguros de que los principios de la ciencia demostrativa no son, como los principios platónicos, meras condiciones de inteligibilidad, sin referente alguno en la realidad?

Uno de los problemas que hay que abordar es, entonces, la justificación de los principios. ¿Cómo sabemos que son verdaderos, si sabemos que son indemostrables? Esto se relaciona con otros dos problemas: ¿cómo llegamos a conocerlos, por medio de qué operación los aprehendemos, puesto que no son innatos? Y ¿qué relación tienen con el mundo? ¿Cómo es que esos principios consiguen explicar algo acerca del mundo sin ser, como los principios platónicos, quimeras?

Para Aristóteles la lógica no es una disciplina independiente de la investigación científica y que por su formalismo pueda llegar a convertirse en una construcción intelectual que no tenga nada que ver con el mundo y que no se ocupe de la verdad o falsedad de los juicios, sino solamente de la corrección de los razonamientos. Aristóteles estudió, sí, las leyes que rigen los razonamientos correctos, pero no llegó a concebir realmente una lógica formal, como trataré de mostrar a continuación.

28 An. Post. I,2, 71b21. 


\section{La lógica aristotélica como un instrumento para la tarea científica}

¿Qué fue realmente lo que descubrió Aristóteles? Que haya descubierto la lógica no quiere decir que haya descubierto las inferencias lógicas como tales. Platón usaba de manera cotidiana la inferencia y la deducción; ${ }^{29}$ decir que Aristóteles "las inventó" o "descubrió" es tanto como decir que el primer geómetra "inventó" la recta al "descubrir" que es la distancia más corta entre dos puntos - esto lo "sabe", sin necesidad de estudiar geometría, cualquier persona que camina en línea recta para llegar de un lugar A a uno B en el menor tiempo posible-. De igual manera, casi cualquier persona, sin necesidad de estudiar lógica, es capaz de razonar de la siguiente manera: "Todos los persas son enemigos; Darío es persa; Darío es un enemigo". Nadie, sin embargo, había formalizado hasta entonces esos razonamientos cotidianos y evidentes, para encontrar las reglas con base en las cuales es posible elaborar y evaluar otros razonamientos cuya validez no es tan evidente. La ausencia de una lógica formal en Platón le hizo cometer tantos errores que, según Bochenski, la lectura de sus diálogos es "casi intolerable" para un lógico (1951, p. 17). Lo que Aristóteles hizo fue tratar de desentrañar, por primera vez, la estructura de los razonamientos. El resultado fue su doctrina del silogismo ( $\sigma \nu \lambda \lambda o \gamma \iota \sigma \mu o ́ \varsigma)$, término que él no inventó, sino que extrajo del

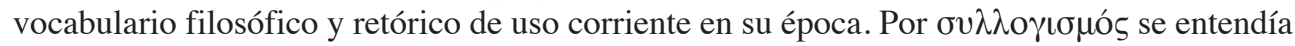
ya algo parecido a una deducción o una inferencia en el ejercicio dialéctico y retórico. El término proviene seguramente del verbo $\sigma v \lambda \lambda \hat{\varepsilon} \gamma \omega$ (recolectar, juntar, unir) y su sustantivo

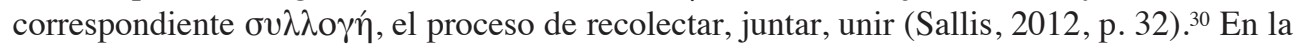
definición de $\sigma v \lambda \lambda \sigma \gamma \iota \sigma \mu o ́ s$ que Aristóteles da al inicio de los Analíticos primeros se aprecia a grandes rasgos lo que quiere analizar: una deducción ( $\sigma v \lambda \lambda \sigma \gamma \iota \sigma \mu o ́ \varsigma)$ es "un discurso ( $\lambda$ ó $\gamma$ os) en el que, sentadas ciertas cosas, se sigue necesariamente algo distinto de lo ya establecido, por el darse estas cosas". ${ }^{31}$ Claramente, Aristóteles se refiere a una clase de lo que hoy en día llamamos consecuencia lógica: una deducción es una clase de discurso tal que, sentadas ciertas premisas, se sigue con necesidad una conclusión distinta de las premisas.

Para desentrañar la estructura de la deducción, Aristóteles tuvo que estudiar por sepa-

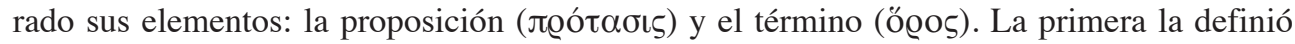
como "un discurso ( $\lambda$ ó $\mathrm{O}$ ऽ) afirmativo o negativo de algo acerca de algo". ${ }^{32} \mathrm{Y}$ el segundo como "aquello en lo que se descompone la proposición, v. g.: el predicado y aquello sobre lo que se predica, con la adición del ser o el no ser". ${ }^{33}$ El análisis de la deducción condujo a

29 El pasaje más socorrido es Fedón 100a. Paul Shorey $(1924,1933)$ usó sobre todo ese pasaje para intentar mostrar que la dialéctica platónica anticipa casi toda la lógica aristotélica excepto la exposición explícita del silogismo. En mi opinión, su tesis es forzada y no proporciona suficiente evidencia textual para soportarla. A. C. Lloyd, en su libro The Anatomy of Platonism (1990, p. 29), menciona a Olimpiodoro, quien en su Comentario a las Categorías (Prolegomena, 17) aseguraba que "Platón sabía demostrar pero no cómo construir una demostración, igual que quienes saben vestir unos zapatos no saben necesariamente cómo hacerlos".

30 Esta explicación la encontré en Sallis J., Logic of Imagination: The Expanse of the Elemental, Indiana University Press, 2012, p. 32.

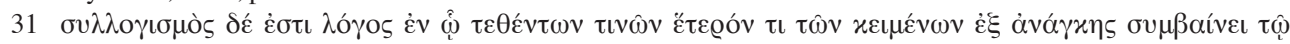

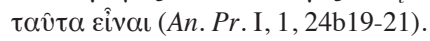

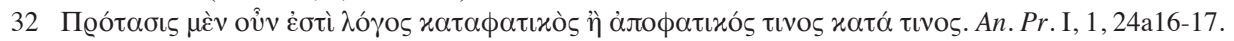

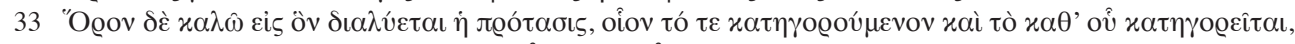

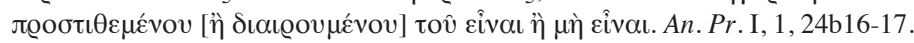




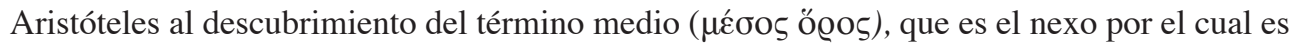
posible unir otros dos términos y concluir algo distinto a lo establecido en las premisas. Al darse cuenta de que el término medio podía ocupar diversos lugares, desarrolló sus famosas tres figuras ( $\sigma \chi \eta \dot{\eta} \mu \alpha \tau \alpha)$, de acuerdo con la posición del término medio en las premisas y considerando los cuatro tipos de proposición que analiza con detalle en De interpretatione (universal afirmativa, universal negativa, particular afirmativa y particular negativa). ${ }^{34}$ En la primera figura el término medio es predicado del término menor (el sujeto de la conclusión) y se predica de él el término mayor (el predicado de la conclusión). En la segunda el término medio es predicado de ambos, y en la tercera el sujeto. Llama la atención, desde la Antigüedad, que Aristóteles no haya tomado en cuenta la cuarta figura, en la cual el término medio se predicaría del término mayor y de él se predicaría el término menor. Un ejemplo de un silogismo de cuarta figura es el siguiente:

Premisa 1: todo león es cuadrúpedo.

Premisa 2: ningún cuadrúpedo es hombre.

Conclusión: ningún hombre es león.

Desde el punto de vista estrictamente lógico no hay razones para ignorar la cuarta figura, que fue desarrollada después por los comentadores e incluida en las clasificaciones medievales de los silogismos. Ross piensa que la cuarta figura no fue considerada por Aristóteles porque no refleja nuestro modo de razonar (Ross, 1949, p. 35) Para un lógico moderno, esta justificación sería bastante débil: la lógica no sólo trata de superar las ambigüedades de los lenguajes naturales, sino también de superar las posibilidades de éstos desde el punto de vista deductivo: así como las matemáticas permiten la resolución de problemas que no se podrían resolver sin abstracción de por medio, la lógica también posibilita el hallazgo de consecuencias e inconsistencias que no resultan evidentes en el lenguaje natural.

Para Aristóteles, sin embargo, la lógica no es una disciplina independiente, sino un instrumento para la tarea científica, y como tal, debe ser capaz entonces de articular de manera natural la realidad y hacer una aportación significativa a nuestro conocimiento. La lógica moderna se concentra en el aspecto formal de los razonamientos, dejando a un lado la materia. Aristóteles, en cambio, no concibe los silogismos como estructuras meramente formales, sino como razonamientos capaces de expresar algo significativo. Alejandro anota en su comentario a los Analíticos primeros que "Aristóteles se fija en los significados (cuando las mismas cosas son significadas) más que en las palabras". ${ }^{35}$ Tanto la deducción como las proposiciones usadas en ella son para Aristóteles una clase de $\lambda$ ó $\gamma \circ \varsigma$, que es definido en

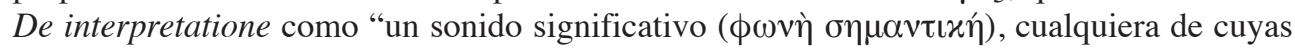

34 Cf. An.Pr. I, 32, 47b13.

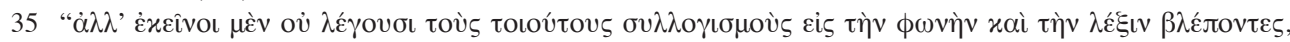

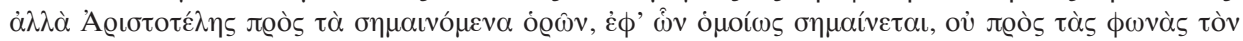

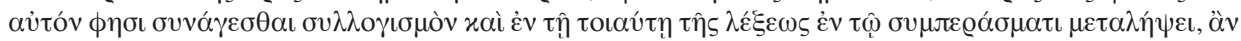

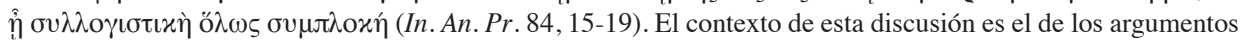
llamados "subsilogísticos” por los estoicos (Cf. Bobzien, 2003, p. 122; Lukasiewicz, 1957, p. 15). 
partes es significativa por separado como enunciación, pero no como afirmación" ${ }^{36}$ Paolo Biondi y Jonathan Barnes han insistido en el aspecto significativo de la lógica aristotélica: el discurso ( $\lambda$ ó $\mathrm{O} \circ$ ) implica no solamente el acto de hablar (o escribir), sino también de decir algo. En este contexto el $\lambda$ ó $\gamma$ os es precisamente lo que se dice.$^{37} \mathrm{La}$ formalización aristotélica de la deducción, entonces, que es probablemente su mayor contribución a la lógica, no implica que para él una deducción deba ser considerada como tal al margen del significado. La formalización sirve para explicitar las leyes deductivas que harían una deducción (con premisas y conclusión significativas) válida. Pero como apunta Orna Harari, la silogística de Aristóteles se diferencia de la lógica formal moderna en que para él la implicación depende no solamente del valor de verdad de las premisas, sino también de una relación (real) de subordinación o coordinación entre los términos (2004, pp. 63-81). Esta relación se expresa al atribuir un sujeto a un predicado. Cuando se comprende el significado de cada uno de los términos de las dos premisas y el significado de la relación establecida entre los términos (por medio de la predicación), necesariamente se asiente a la conclusión. Predicar implica, entonces, conocer el significado de los términos y saber si aquello que se predica es compatible o no con aquello de lo cual se predica. Por ello la predicación depende de la definición. Como apunta Paolo Biondi, "es necesario que cada término signifique algo definido y unitario. En lógica, eso quiere decir usar solamente términos-conceptos unívocos, conceptos que expresan sin ambigüedad sólo un significado" (Biondi, 2004, p. 77) Lo anterior resulta claro en Metafísica $\Gamma$, 4, donde Aristóteles dice que si los nombres no tuvieran un significado único y determinado, la comunicación sería imposible. ${ }^{38}$ La importancia de la definición se hace patente también en la preocupación de Aristóteles por reducir la segunda y la tercera figura a la primera. Nuevamente, desde el punto de vista meramente formal, no se puede justificar esta reducción, pues las tres figuras son igualmente válidas, la única diferencia está en el arreglo de los términos. Pero Aristóteles explica que si buscamos la verdad, el orden de los tres términos silogísticos tiene que concordar con ella (con la manera en la que esos tres términos se relacionan en la realidad). ${ }^{39}$ Ross explica que la segunda y la tercera figura proveen la ratio cognoscendi de la conclusión, pero no la ratio essendi $(1949$, p. 33)

Lo dicho arriba abre la pregunta de hasta qué punto la lógica de Aristóteles puede ser entonces considerada formal -y para la lógica moderna, en general, esta pregunta es un sinsentido, pues si se trata realmente de una lógica, tiene que ser formal- . Hay varias razones para considerarla así: en primer lugar, Aristóteles usa símbolos (letras del alfabeto griego) para designar términos. Este uso de variables es interpretado como un signo de que su interés está puesto en la forma de los razonamientos y no en el contenido. Revela una conciencia del aspecto estructural que la lógica debe atender, independientemente de la materia de los conceptos (significados en los términos) y su referencia a objetos. En segundo lugar, gracias al uso de variables, la consecuencia lógica es determinada desde el punto de vista formal, lo

$36 \Lambda$

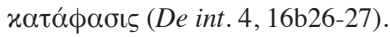

37 "It is true that no English word will pick out the range of meaning of logos. But that does not make logos a puzzling, let alone a metaphysically exciting, term. The central idea is perfectly simple: a logos is what you say" (Barnes, 1991, p. 19; cf. Biondi, 2004, p. 70).

38 Met. Г, 4, 1006a29-b12.

39 An. Pr. I: 30, 46a4-11. 
cual quiere decir que la validez o invalidez de los razonamientos es indiferente al contenido de los términos. Los silogismos válidos lo son no porque la conclusión y las premisas sean verdaderas, sino porque las premisas conducen con necesidad a la conclusión. Por ello, el siguiente silogismo resultaría válido:

p1: todo hombre es un cerebro en una cubeta.

p2: todo cerebro en una cubeta es una manzana.

c: todo hombre es una manzana.

El silogismo anterior es válido porque su forma es válida:

Premisa 1: todo A es B

Premisa 2: todo B es C.

Conclusión: todo A es $\mathrm{C}$

Si atendemos a lo dicho arriba sobre el aspecto significativo de la lógica aristotélica, sin embargo, no resulta tan claro que la lógica de Aristóteles, tal como aparece en los Analíticos, pueda ser comprendida de esta manera. Desde el surgimiento de la lógica matemática en la segunda mitad del siglo XIX se puede reconocer entre los lógicos e historiadores de la lógica una tendencia generalizada a leer la lógica aristotélica con los ojos de la lógica moderna. Esto ha dificultado a menudo la comprensión de los textos, pues la mayoría de los filósofos profesionales aprende en el bachillerato y en la universidad una "lógica aristotélica" que no es genuinamente aristotélica, sino que es más bien, en algunos aspectos, la interpretación moderna de la lógica aristotélica.

Un buen ejemplo de esta tendencia es el libro de Jan Lukasiewicz, Aristotle's Syllogistic from the Standpoint of Modern Formal Logic. En este libro Lukasiewicz critica a quienes entienden la lógica aristotélica, o la lógica en general, como un análisis de las formas del pensamiento:

Las leyes de la lógica no tienen que ver con tus pensamientos en mayor grado que las de las matemáticas. A lo que en la lógica se llama "psicologismo" es un signo de la decadencia de la lógica en la filosofía moderna. De esta decadencia Aristóteles no es responsable de ninguna manera. A lo largo de los Analíticos primeros, donde se expone sistemáticamente la teoría del silogismo, no existe un solo término psicológico. Aristóteles sabe, con una certeza intuitiva, qué pertenece a la lógica, y entre los problemas tratados por él no hay uno solo que se conecte con un fenómeno físico como el de pensar (1957, p. 13).

La intención de Lukasiewicz resulta clara: él quiere purificar la lógica aristotélica de todo elemento psicologista, semántico, incluso filosófico. Reconoce, sin embargo, que Aristóteles no da una respuesta a la pregunta sobre cuál es el objeto de la lógica. "La respuesta a esta pregunta no es dada por Aristóteles, sino por sus seguidores, los peripatéticos" (Lukasiewicz, 1957, p. 13). A continuación parafrasea a Amonio, quien en su comentario a los Analíticos primeros explica que si los silogismos son hechos con términos concretos, como hace Pla- 
tón al probar silogísticamente que el alma es inmortal, entonces la lógica es tratada como parte de la filosofía. Pero si se toman los silogismos como reglas puras expresadas con letras, como hacían los peripatéticos siguiendo a Aristóteles, entonces la lógica es tratada como un instrumento de la filosofía. ${ }^{40}$ Esta explicación coincide a grandos rasgos con la lectura de Amonio, Filópono y Alejandro de Afrodisias que Tae-Soo Lee hace en su libro Die griechische Tradition der aristotelischen Syllogistik in der Spätantike (1984). Tae-Soo Lee muestra que los tres comentadores entienden la lógica de Aristóteles como un instrumento para la filosofía - al modo peripatético-, por lo que su concepción de la lógica es genuinamente formal.

Lecturas como la de Lukasiewicz son sin duda sugerentes y válidas - lo que hace en su libro está anunciado en el título: interpretar la lógica aristotélica desde el punto de vista moderno - , pero no aportan demasiado a la comprensión interna de los textos de Aristóteles. Lukasiewicz polemiza contra una lectura psicologista de la lógica aristotélica, pero sus alternativas tampoco son aristotélicas: que la lógica de Aristóteles poco tenga que ver con el estudio de las leyes del pensamiento - como se suele definir el objeto de la lógica en algunos manuales que él critica-, no muestra que sea cercana a la concepción moderna de lógica.

\section{Conclusión}

Hay una diferencia fundamental entre la lógica aristotélica y la lógica moderna. Como hemos dicho arriba, puesto que la deducción es una clase de $\lambda$ ó $\gamma$ os y como tal debe tener un contenido significativo, la inferencia silogística en Aristóteles se basa en relaciones conceptuales de subordinación y coordinación, por lo que la consecuencia lógica no depende únicamente, como en la lógica moderna, del valor de verdad de los operadores lógicos. Para la lógica aristotélica, por ejemplo, es posible inferir a partir de un juicio universal, de manera inmediata, el juicio particular correspondiente: si se afirma que "todos los hombres son mortales", se puede inferir, de acuerdo con el cuadro de oposición, que "algún hombre es mortal". Para la lógica moderna, sin embargo, esta inferencia resulta inválida. El juicio universal afirmativo se simboliza como $(\mathrm{x})(\phi \mathrm{x} \supset \psi \mathrm{x})$ y el particular afirmativo como $(\exists \mathrm{x})$ $(\phi x \cdot \psi \mathrm{x})$. El primero expresa que para todo $\mathrm{x}$, si $\mathrm{x}$ es $\phi$, entonces $\mathrm{x}$ es $\psi$. El segundo que existe al menos algún $\mathrm{x}$ tal que $\mathrm{x}$ es $\phi$ y x es $\psi$. Si en el juicio universal afirmativo se sustituyen las variables por constantes, de modo que $\mathrm{U}$ sea unicornio y $\mathrm{C}$ cornúpeta, obtenemos (x) (UxつCx). Dado que no hay unicornios, todo ejemplo de sustitución de Ux es falso, y al ser falso el antecedente del condicional, el enunciado resulta verdadero (la única manera de que el condicional sea falso es que el antecedente sea verdadero y el consecuente falso). $(\exists \mathrm{x})(\mathrm{Ux} \bullet \mathrm{Cx})$ no puede inferirse de $(\mathrm{x})(\mathrm{Ux} \supset \mathrm{Cx})$, pues lo que $(\exists \mathrm{x})(\mathrm{Ux} \bullet \mathrm{Cx})$ expresa es que existe al menos un $x$ tal que es un unicornio y es cornúpeta, lo cual, hasta donde sabemos, es falso. La inferencia inmediata que es posible en la lógica aristotélica quedaría expresada de la siguiente manera: $[(\mathrm{x})(\mathrm{Ux} \supset \mathrm{Cx})] \supset[(\exists \mathrm{x})(\mathrm{Ux} \bullet \mathrm{Cx})]$. Por lo dicho arriba, resulta una inferencia inválida, pues el antecedente es verdadero y el consecuente falso.

Las razones por las cuales la inferencia inmediata sí es válida dentro de la lógica aristotélica tienen que ver, en primer lugar, con razones extralógicas. Para él es evidente que si

40 Amonio, In. Pr. An., 10, 36. 
algo se predica del género, se predica también de la especie y del individuo. Esto es válido en todos los casos porque para la lógica de Aristóteles las substancias no existentes son irrelevantes. En un pasaje de los Analíticos posteriores explica que si algo no es (no existe),

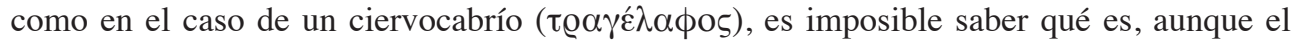
nombre signifique algo ${ }^{41}$ La lógica es un instrumento auxiliar para la ciencia y la ciencia se ocupa, entre otras cosas, de la búsqueda de definiciones: ${ }^{42}$ lo que no existe no puede ser definido, porque no tiene una esencia. Por lo tanto, a la lógica le son indiferentes las entidades no existentes.

En segundo lugar, como apunta Orna Harari, puesto que la lógica de Aristóteles se basa en relaciones conceptuales y no en los valores de verdad asignados a los operadores, "la conclusión se deriva de la comprensión del contenido enunciado en las premisas" (2004, p. 79). Harari explica que la lógica de Aristóteles es una formalización de la comprensión (understanding), mientras que la lógica moderna formaliza el juicio: "la primera trata de establecer, en términos generales, cómo un contenido se sigue de otro, mientras que la segunda especifica las condiciones bajo las cuales un juicio (i. e. valor de verdad) se sigue de otro" (2004, p. 81). Que un contenido se siga de otro implica que para Aristóteles existe una relación real de subordinación entre los términos. La predicación (afirmativa) es definida por él en los Analíticos primeros de la siguiente manera: "el que una cosa esté [contenida] en el conjunto de otra y el que una cosa se predique acerca de toda otra es lo mismo. Decimos que se predica acerca de cada uno cuando no es posible tomar nada acerca de lo cual no se diga el otro término; y de igual manera en el caso de ninguno". ${ }^{43}$ La inferencia silogística depende de esta noción de predicación, pues el término mayor no lo es solamente por el lugar que ocupa en la conclusión, sino sobre todo porque el término medio está contenido en él; el término menor, por su parte, es término menor porque está subordinado al término medio (1957, p. 30). Lukasiewicz señala acertadamente que entonces algunas inferencias válidas quedarían excluidas en la silogística de Aristóteles. Por ejemplo:

Todos los cuervos son pájaros.

Algunos animales son cuervos

Por lo tanto: algunos animales son pájaros.

Este silogismo, que corresponde al modo DARII según la clasificación medieval, no se ajusta a las exigencias que Aristóteles establece, porque el término con mayor extensión, "animal", es el término menor; "pájaro", medio en extensión, es el término mayor. Y el término con menor extensión, "cuervo", es el término medio. ¿Cómo se puede justificar el hecho de que la lógica de Aristóteles excluya estas inferencias válidas? Podría pensarse que Aristóteles simplemente incurre en un error, que al ser pionero en la lógica no consiguió llegar a un grado suficiente de sofisticación como para descubrir la validez de tales inferencias. Pero lo cierto es que Aristóteles está consciente de que formalmente son

\footnotetext{
41 An. Post. II, 7, 92b6-8.

42 Cf. Top. I,5, 102a32-39.

43 An. Pr. I, 1, 24b27-30.
} 
válidas: pero su validez es trivial, pues este tipo de inferencias no contribuye en nada a aumentar nuestro conocimiento de la realidad.

En conclusión, la lógica aristotélica puede considerarse "formal" si se toma en cuenta que Aristóteles sí descubrió, por supuesto, el aspecto formal de la lógica, en términos de validez lógica. Al mismo tiempo, sin embargo, nunca prescindió - en sus mismas investigaciones lógicas - de ciertas consideraciones extralógicas que garantizaban la utilidad de la lógica como un instrumento al servicio de la investigación científica. En ese sentido, hay que subrayar la importancia que tenía para él atender no solamente a la forma de los razonamientos, sino también al significado de los términos y a lo que los juicios y los silogismos expresan acerca del mundo y los entes. En concordancia con su realismo metafísico, Aristóteles le asignó a la lógica - igual que a las matemáticas - un papel secundario y meramente instrumental.

\section{Referencias}

Aristóteles (1995), Tratados de lógica I \& II. Trad. Miguel Candel Sanmartín. Madrid: Gredos.

Aristóteles (1982), Metafísica. Trad. Valentín García Yebra. Madrid: Gredos.

Alejandro de Afrodisias (1991), On Aristotle Prior Analytics 1.1-7. Ithaka: Cornell University Press.

Barnes, J. (1981), "Proof and the Syllogism”. En Berti E. (Ed.) Aristotle on Science: The Posterior Analytics. Proceedings of the Eight Symposium Aristotelicum (pp. 34-57). Padua: Editrice Antenore.

Barnes, J. (Trad.). (1991), “Introduction”. En Alejandro de Afrodisias (1991) pp. 1-7.

Biondi, P. (2004), Aristotle: Posterior Analytics II.19. Canadá: Les Presses de l’Université Laval.

Bobzien, S. (2003), "Logic". En B. Inwood (Ed.), The Cambridge Companion to the Stoics (pp. 85-123), Cambdrige: Cambridge University Press.

Bochenski, J. M. (1951), Ancient Formal Logic Studies in Logic and the Foundations of Mathematics. Amsterdam: North-Holland Publishing Company.

Bolton, R. (1990), "The Epistemological Basis of Aristotelian Dialectic". En D. Devereux \& P. Pellegrin (Eds.), Biologie, Logique Et Metaphysique Chez Aristote (pp. 185-236). Paris: Editions du Cnrs.

Cherniss, H. (1962), The Riddle of the Early Academy. New York: University of California Press.

During, I. (2000), Aristóteles. México: UNAM.

Harari, O. (2004), Knowledge and Demonstration: Aristotle's Posterior Analytics. Kluwer Academic Publishers.

Hintikka, J. (1997), "What was Aristotle doing in his early logic, anyway? A reply to Woods and Hansen". Synthese, 113(2), 241-249.

Huby, P. M. (1962), "The Date of Aristotle's Topics and its Treatment of the Theory of Ideas". Classical Quarterly, 12(01), 72-80.

Lee, T. (1984), Die griechische Tradition der aristotelischen Syllogistik in der Spätantike. Gotinga. 
Lloyd, A. C. (1990), The Anatomy of Platonism. Oxford: Clarendon Press.

Lukasiewicz, J. (1957), Aristotle's Syllogistic From the Standpoint of Modern Formal Logic. Oxford: Oxford University Press.

Maier, H. (1897), "Die Syllogistik des Aristoteles". Philosophical Review, 6(n/a), 439.

Platón, (1985), Protágoras. En Diálogos I. Trad. Calonge J., Lledó E. \& García C. Madrid: Gredos.

Platón, (1983), Gorgias. En Diálogos II. Trad. Calonge J., Acosta E., Olivieri F. J. \& Calvo J. L. Madrid: Gredos.

Platón, (1986), Fedón, Banquete, Fedro. En Diálogos III. Trad. García C., Martínez M. \& Lledó E. Madrid: Gredos.

Platón, (1986), República. En Diálogos IV. Trad. Eggers Lan C. Madrid: Gredos.

Ross, W. D. (1949), “Aristotle's Prior and Posterior Analytics". Philosophy, 25(95), 380-382.

Sallis, J. (2012), Logic of Imagination: The Expanse of the Elemental. Bloomington: Indiana University Press.

Shorey, P. (1924), "The Origin of Syllogism". Classical Philology, XIX(I), 1-19.

Shorey, P. (1933), "The Origin of the Syllogism Again". Classical Philology, XXVIII(3), 199-204.

Smith, R. (2009), "None of the Arts that Gives Proofs about Some Nature is Interrogative". En M. Sintonen (Ed.), The Socratic Tradition: Questioning as Philosophy and as Method10 (Texts in Philosophy, Vol. 10, pp. 25-49). London: College Publications.

Stephens, J. (1993), "Plato on dialectic and dialogue". En The Journal of Value Inquiry (Vol. 27, pp. 465-473).

White, N. P. (2006), "Plato's metaphysical epistemology". En Kraut R. (Ed.), The Cambridge Companion to Plato (pp. 277-310). Cambridge: Cambridge University Press. 
